\title{
A EDUCAÇÃO E O PLANO NACIONAL DE EDUCAÇÃO EM DIREITOS HUMANOS: EFETIVANDO OS DIREITOS FUNDAMENTAIS NO BRASIL
}

\section{EDUCATION AND NATIONAL EDUCATION IN HUMAN RIGHTS: COMMITTING FUNDAMENTAL RIGHTS IN BRAZIL}

\author{
Clovis Gorczevski ${ }^{1}$ \\ Letícia Regina Konrad²
}

\section{RESUMO}

Os direitos humanos devem ser condutores para a manutenção da paz social e principalmente da democracia no Estado Democrático de Direito, uma vez que representam valores sociais reconhecidos historicamente. Entretanto, estes só poderão ser praticados quando verdadeiramente conhecidos e percebidos por toda a humanidade. Nesse sentido, a educação apresenta-se como uma ferramenta essencial na construção de tal realidade. No presente artigo abordar-se-á os direitos humanos e os direitos fundamentais, dando ênfase à diferenciação doutrinária existente entre ambos, destacando-se posteriormente a educação como ferramenta de emancipação e libertação social para concretização dos direitos humanos. Ainda analisar-se-á o II Plano Nacional de Educação em Direitos Humanos, uma política pública de Estado, que aborda a dimensão atual do significado da educação em direitos humanos e a consequente efetivação dos direitos fundamentais.

PALAVRAS-CHAVE - Educação. Direitos Humanos. Direitos Fundamentais. II Plano Nacional de Educação em Direitos Humanos.

\footnotetext{
${ }^{1}$ Advogado, doutor em direito (Universidad de Burgos, 2001), pós-doutor em direito (CAPES Universidad de Sevilla, 2007), pós-doutor (CAPES - Fundación Carolina - Universidad de La Laguna, 2010). Professor-pesquisador do Programa de PPGD - Mestrado/Doutorado da Universidade de Santa Cruz do Sul - UNISC. E-mail: clovis.g@terra.com.br ${ }^{2}$ Mestranda em Direitos Sociais e Políticas Públicas na Universidade de Santa Cruz do Sul UNISC, linha de pesquisa Constitucionalismo Contemporâneo. Bolsista CAPES. Integrante do grupo de Pesquisa Direitos Humanos coordenado pelo Prof. Pós Dr. Clóvis Gorczevski, vinculado ao Programa de Pós-Graduação em Direito, Mestrado e Doutorado - UNISC. Advogada. Especialista em Direito Civil com ênfase em família e sucessões. Mediadora Familiar. E-mail: leticiakonrad@gmail.com.
} 
ABSTRACT - Human rights must be conductive to the maintenance of social peace and democracy especially in a democratic state, as they represent social values recognized historically. However, these may only be performed when truly known and perceived by all mankind. In this sense, education is presented as an essential tool in the construction of such a reality. In the present article will address human rights and fundamental rights, emphasizing the doctrinal distinction between both, especially later education as a tool of empowerment and social liberation for realization of human rights. Still will analyze the II National Plan for Human Rights Education, a public policy of the State, which addresses the current dimension of the meaning of human rights education and the consequent enforcement of fundamental rights

KEYWORDS - Education. Human Rights. Fundamental Rights. II National Plan for Human Rights Education.

\section{CONSIDERAÇÕES INICIAS}

A Declaração Universal dos Direitos Humanos (DUDH) de 1948 da Organização das Nações Unidas (ONU) desencadeou uma grande mudança no comportamento social mundial, resultando na base de muitos sistemas de proteção dos direitos humanos. O seu legado resta evidente quando valores como cidadania, democracia e participação dos indivíduos na construção de uma sociedade pautada pela busca de igualdade e solidariedade aparecem como conteúdo significativo da educação, em especial, da educação em direitos humanos.

Educar em direitos humanos é promover o conhecimento dos direitos humanos de modo que sejam percebidos não só como direito, mas também como dever de promoção de todos para a garantia da paz social no mundo. Trata-se de prevenir o retrocesso àqueles direitos violados quando da Segunda Guerra Mundial, na qual foram cometidas atrocidades contra a humanidade. Tais horrores e barbáries não mais podem ser aceitos na atualidade, pois distantes dos valores da ética e da justiça. 
Portanto, os direitos humanos devem ser condutores para a manutenção da paz social e principalmente da democracia no Estado Democrático de Direito e, só poderão ser praticados quando realmente conhecidos e praticados por toda a sociedade. Nesse contexto, verifica-se o papel primordial da educação, ferramenta constante para a busca e desenvolvimento de autonomia e emancipação social dos indivíduos.

No presente artigo pretende-se inicialmente abordar os direitos humanos e os direitos fundamentais, esclarecendo brevemente a diferenciação doutrinária existente entre as várias correntes de pensamento, viabilizando um maior entendimento sobre a temática. Após, trar-se-á à baila o papel da educação, dando-se enfoque especial para a necessidade iminente de uma educação libertadora e emancipadora, voltada para a concretização dos direitos humanos. E, por fim, a partir do Programa Nacional de Educação em Direitos Humanos, chegar-se-á ao II Plano Nacional de Educação em Direitos Humanos, política pública que traz consigo um marco da valorização e afirmação de uma educação em direitos humanos no atual Estado Democrático de Direito.

Destaca-se que o II Plano Nacional de Educação em Direitos Humanos é vislumbrado como imprescindível para a concretização efetiva dos direitos fundamentais no Brasil, vez que os direitos humanos são uma conquista cotidiana na história da humanidade.

Para tanto, considerando-se que o presente artigo tem natureza bibliográfica, utilizar-se-á o método de abordagem dedutivo.

\section{DOS DIREITOS HUMANOS E FUNDAMENTAIS}

Os direitos humanos não são apenas aqueles positivados, mas sim valores superiores que perduram ao longo do tempo e estão em constante transformação, apresentando um reconhecimento histórico (Gorczevski, 2009). Eles nascem com o homem, são universais, fundamentais, inalienáveis, absolutos, exigíveis em qualquer Estado, representando condições mínimas para uma vida digna. Daí seu entendimento no sentido que são unicamente pré-estatais, ou naturais, não dependendo da sociedade para ter efetividade e cabendo ao Estado a sua proteção. 
Para Pérez Luño (1999, p. 48) os direitos humanos aparecem como um "conjunto de faculdades e instituições que, em cada momento histórico, concretiza as exigências da dignidade, da liberdade, da igualdade humana", as quais devem ser reconhecidas positivamente pelo ordenamento jurídico nacional e internacional.

Para Bobbio (2004), os direitos humanos são históricos, modificáveis, suscetíveis de constante transformação e alargamento de seus horizontes, não sendo produto da natureza, mas sim da civilização humana.

\begin{abstract}
Sabemos hoje que também os direitos ditos humanos são o produto não da natureza, mas da civilização humana; enquanto direitos históricos, eles são mutáveis, ou seja, suscetíveis de transformação e de ampliação. Basta examinar os escritos dos primeiros jusnaturalistas para ver quanto se ampliou a lista dos direitos: Hobbes conhecia apenas um deles, o direito à vida. Como todos sabem, 0 desenvolvimento dos direitos do homem passou por três fases: num primeiro momento, afirmaram-se os direitos de liberdade, [...] num segundo momento, foram promulgados os direitos políticos, [...] finalmente, foram proclamados os direitos sociais, que expressam 0 amadurecimento de novas exigências - podemos dizer de novos valores [...]. (BOBBIO, 2004, p. 32)
\end{abstract}

Nesse diapasão, os direitos humanos são valores superiores que existem no mundo axiológico, enquanto que os direitos fundamentais, nomenclatura do mundo jurídico, são os direitos humanos positivados, trazidos para o mundo real (GORCZEVSKI, 2009).

Os direitos humanos são pervertidos no exato momento em que se tomam objeto de tratamento jurídico, pois, concebidos historicamente como um mecanismo de proteção dos cidadãos livres contra o arbítrio dos governantes [...] eles são esvaziados na medida em que é o próprio Estado que os regulamenta. (LEAL, 1997, p. 154)

Pérez Luño (2005, p. 44) evidencia que os direitos humanos e os direitos fundamentais são utilizados muitas vezes como sinônimos. Realça que a doutrina tem enfatizado que direitos fundamentais designam os direitos positivados internamente e direitos humanos são os direitos naturais positivados nas declarações e convenções internacionais, assim como as exigências básicas relacionadas com a dignidade, liberdade e igualdade da pessoa que não tem alcançado um estatuto jurídico positivo. 
Los derechos humanos aúnan, a su significación descriptiva de aquellos derechos y libertades reconocidos em las declaraciones y convenios internacionales, una connotación prescriptiva o deontológica, al abarcar también aquellas exigencias más radicalmente vinculadas al sistema de necessidades humanas, y que debiendo ser objeto de positivación no lo han sido. Los derechos fundamentales poseen un sentido más preciso y estricto, ya que tan sólo describen el conjunto de derechos y libertades jurídica e institucionalmente reconocidos y garantizados por el Derecho positivo. Se trata siempre, por tanto, de derechos delimitados espacial y temporalmente, cuya denominación responde a su carácter básico o fundamentador del sistema jurídico político del Estado de Derecho. (grifo do autor) (PÉREZ LUÑO, 2005, p. 47)

Pode-se dizer que os direitos fundamentais nascem da positivação dos direitos humanos, como também aponta Canotilho:

\begin{abstract}
as expressões direitos dos homem e direitos fundamentais são frequentemente utilizadas como sinônimas. Segundo a sua origem e significado poderíamos distingui-las da seguinte maneira: direitos do homem são direitos válidos para todos os povos e em todos os tempos; direitos fundamentais são os direitos do homem, jurídicoinstitucionalmente garantidos e limitados espaço-temporalmente. Os direitos do homem arrancariam da própria natureza humana e daí o seu caráter inviolável, intertemporal e universal; os direitos fundamentais seriam os direitos objetivamente vigentes numa ordem jurídica concreta (CANOTILHO, 1998, p. 259).
\end{abstract}

Para Canotilho, a positivação dos direitos fundamentais significa a incorporação dos direitos naturais e inalienáveis do indivíduo na ordem jurídica positiva. Antes de positivados os direitos são mera "retórica política" e não direitos constitucionalmente protegidos sob forma de normas constitucionais, entenda-se regras e princípios (CANOTILHO, 1998, p. 347).

Alexy denota que há uma relação muito tênue entre os direitos humanos e os direitos fundamentais. Os direitos humanos seriam universais, fundamentais, preferenciais, abstratos e morais. Entretanto, é justamente a moralidade que proporciona um "caráter suprapositivo", distinguindo os direitos humanos dos direitos fundamentais. Para o autor, direitos fundamentais "são direitos que foram acolhidos em uma constituição com o intuito e com a intenção de positivar os direitos do homem" (ALEXY, 2008, p. 10).

Direitos fundamentais são direitos públicos-subjetivos de pessoas (físicas ou jurídicas), contidos em dispositivos constitucionais e, portanto, que encerram caráter normativo supremo dentro do Estado, tendo como finalidade limitar o exercício do poder estatal em face da liberdade individual (DIMOULIS; MARTINS, 2011, p. 49). 
Sarmento também esclarece que os direitos fundamentais não são "entidades estéreas, metafísicas, que sobrepairam o mundo real. Pelo contrário, são realidades históricas, que resultam de lutas e batalhas travadas no tempo, em prol da afirmação da dignidade humana" (SARMENTO, 2004, p. 18). Os direitos fundamentais transformaram-se ao longo do tempo, tanto com relação ao seu conteúdo, quanto à titularidade, eficácia e efetivação (SARLET, 2009, p. 45).

Para Sarlet, direitos fundamentais são direitos humanos reconhecidos e positivados pelo direito constitucional positivo de um Estado, enquanto direitos humanos guardam relação com os documentos de ordem internacional, tratando-se de posicionamentos jurídico-políticos responsáveis pelo reconhecimento de direitos e liberdades ao ser humano, independente de sua vinculação à determinada constituição, apresentando, portanto, um caráter supranacional (SARLET, 2009, p. 32).

\footnotetext{
Direitos fundamentais são, portanto, todas aquelas posições jurídicas concernentes às pessoas, que, do ponto de vista do direito constitucional positivo, foram, por seu conteúdo e importância (fundamentalidade em sentido material), integradas ao texto da Constituição e, portanto, retiradas da esfera de disponibilidade dos poderes constituídos (fundamentalidade formal), bem como as que, por seu conteúdo e significado, possam lhes ser equiparados, agregando-se à Constituição material, tendo, ou não, assento na Constituição formal (SARLET, 2009, p. 85).
}

Sánchez Rubio (2010) destaca que o processo de institucionalização e reconhecimento normativo dos direitos humanos pode acarretar certo vazio de conteúdo, verificando assim a "eficácia minimalista, reduzida e insuficiente" em relação à quantidade esmagadora de abusos cometidos contra os direitos humanos diariamente, bem como tipo de garantias procedimentais que se estabelecem como remédios àqueles. A institucionalização e a normatização dos direitos humanos reduz a efetivação apenas à sua violação, quando evidenciada uma demanda judicial. Entretanto, esclarece o autor que os direitos humanos existem antes mesmo de serem violados, compreendendo sua significação uma grandeza bem maior, dotada de muita luta social e reivindicações populares. Os direitos humanos manifestam-se nas tramas sociais, a partir da dominação à libertação ou emancipação dos sujeitos, 
apresentando-se em práticas sociais e ações diárias de todo e qualquer ser humano, abrangendo desse modo seu significado um conteúdo além do formal.

Pode-se dizer que a Constituição Federal de 1988 alargou a abrangência dos direitos e garantias fundamentais e desde o seu preâmbulo prevê um Estado Democrático de Direito no país, objetivando o exercício dos direitos sociais e individuais, a liberdade, a segurança, o bem-estar, 0 desenvolvimento, a igualdade e a justiça, como valores supremos de uma sociedade fraterna, pluralista e sem preconceitos. A prevalência dos direitos humanos é um princípio que deve nortear a Constituição e o desenvolvimento do Brasil (LEAL, 1997, p. 131).

Hodiernamente, as constituições democráticas têm por base 0 reconhecimento e a proteção dos direitos humanos, sendo a concretização dos direitos fundamentais o fundamento do Estado Democrático de Direito, e condição de sua manutenção.

Portanto, sendo os direitos humanos verdadeiros condutores para a manutenção da paz social e principalmente da democracia no Estado Democrático de Direito, como já inicialmente mencionado, reafirma-se novamente que estes só poderão ser praticados quando verdadeiramente conhecidos, tendo seu significado efetivamente entendido e respeitado por toda a humanidade, com vistas à concretização constante da dignidade da pessoa humana. Assim, a educação pode apresentar-se como uma ferramenta essencial na construção de tal realidade.

\section{DA EDUCAÇÃO}

O reconhecimento da importância da educação na formação do indivíduo e da própria sociedade é evidenciado nas primeiras sociedades politicamente organizadas. Denota-se ao longo da história que a educação era destinada à formação apenas de classes dominantes. Foi somente no século $\mathrm{XVI}$, período da Reforma e do lluminismo, que esta popularizou-se, passando a ocupar um papel de destaque entre intelectuais e políticos, vez que passa a ser vislumbrada como ferramenta única para a transformação da natureza humana no sujeito exigido pelos "novos tempos" (GORCZEVSKI, 2010, p. 39). 
Arendt (2007) destaca ser a tarefa da educação "apresentar o mundo", conscientizando os indivíduos que este mundo é pertencente a um coletivo. Para Arendt, a partir do nascimento o indivíduo vai ser contextualizado no mundo. A natalidade representa, portanto, um novo ser no mundo, que será acolhido e iniciado no mundo já existente a partir da educação, tornando-se para tanto apto ao legado da humanidade que será transmitido ao longo do seu processo educativo.

A educação está entre as atividades mais elementares e necessárias da sociedade humana, que jamais permanece tal qual é, porém se renova continuamente através do nascimento, da vinda de novos seres humanos. Esses recém-chegados, além disso, não se acham acabados, mas em um estado de vir a ser. (ARENDT, 2007, p. 234)

Para a autora Arendt (2007), a preservação do mundo e o amor ao mundo (amor mundi) são fundamentais e devem ser transmitidos pelos adultos para as novas gerações. A educação auxiliará nas responsabilidades do novo ser para com o mundo já existente. Para a autora, a renovação do mundo existente se dá a partir da natalidade, e nascer significa trazer uma nova ordem ao mundo na medida em que incorpora à herança dos adultos às experiências das novas gerações. Nesse contexto entra o papel primordial da educação:

A tarefa da educação é justamente a de apresentar o mundo às gerações do presente, tentando fazê-las conscientes de que comparecem a um mundo que é o lar comum de múltiplas gerações humanas. Ao conscientizá-las do mundo a que vieram, estas deverão compreender a importância de sua relação e ligação com as outras gerações, passadas e vindouras. Tal relação se dará, primeiro, no sentido de preservar o tesouro das gerações passadas, isto é, no sentido de a geração do presente tomar o cuidado de trazer a esse mundo sua novidade sem que isso implique a alteração, até ao irreconhecimento, do próprio mundo, da construção coletiva do passado (FRANCISCO, 2008, p. 34).

Essa responsabilização para com o mundo trazida por Arendt está intimamente ligada à participação, vez que a educação vai contribuir com o processo de emancipação do ser humano, de modo que este tenha autonomia no mundo. Nas palavras de Freire (2001a, p. 40) "Ninguém nasce feito. Vamos nos fazendo aos poucos, na prática social de que tornamos parte". A educação é a ferramenta fundamental para a busca e desenvolvimento da autonomia.

É esta percepção do homem e da mulher como seres "programados, mas para aprender" e, portanto, para ensinar, para conhecer, para intervir, que me faz entender a prática educativa como um exercício 
constante em favor da produção e do desenvolvimento da autonomia de educadores e educandos. Como a prática estritamente humana jamais pude entender a educação como uma experiência fria, sem alma, em que os sentimentos e as emoções, os desejos, os sonhos devessem ser reprimidos por uma espécie de ditadura reacionalista (FREIRE, 1996, p. 54).

A respeito de uma educação libertadora em direitos humanos, o educador Freire propõe a educação numa perspectiva emancipadora a partir da participação:

A educação para os direitos humanos, na perspectiva da justiça, é exatamente aquela educação que desperta os dominados para a necessidade da briga, da organização, da mobilização crítica, justa, democrática, séria, rigorosa, disciplinada, sem manipulações, com vistas à reinvenção do mundo, à reinvenção do poder. [...] essa educação tem que ver com uma compreensão diferente do desenvolvimento, que implica uma participação, cada vez maior, crescente, crítica, afetiva, dos grupos populares (FREIRE, 2001b, p. 99).

Sader (2010, p. 80) vindo ao encontro de Freire, leciona que educar consiste em um "ato de formação da consciência - com conhecimentos, com valores, com capacidade de compreensão" do mundo.

\begin{abstract}
Educar é assumir a compreensão do mundo, de si mesmo, da intrerrelação entre os dois. Pode ser uma compreensão real, que capte os mecanismos que, efetivamente, são produzidos e reproduzidos pelos homens no seu processo concreto de vida, ou, ao contrário, pode ser uma visão alienada que, ao invés de permitir essa compreensão, ocupa esse lugar na consciência das pessoas com mitos, com ilusões, com concepções que consolidem a incapacidade das pessoas de se compreenderem no mundo e compreenderem o mundo que, mesmo sem consciência, estão produzindo e reproduzindo, cotidianamente, nas suas vidas (SADER, 2010, p. 80).
\end{abstract}

A educação é uma ferramenta de emancipação dos indivíduos, na medida em que proporciona a retomada de valores como ética e justiça, aparentemente tão esquecidos. A educação em direitos humanos surge como ferramenta, não só de entendimento, mas de resistência às tentativas de encobrimento de um passado nefasto e doloroso para os indivíduos, vítimas, em diferentes dimensões, das atrocidades de Estados totalitaristas.

A EDUCAÇÃO deve contribuir para a autoformação da pessoa (ensinar a assumir a condição humana, ensinar a viver) e ensinar como se tornar cidadão. Um cidadão é definido, em uma democracia, por sua solidariedade e responsabilidade em relação a sua pátria. $O$ que supõe nele o enraizamento de sua identidade nacional (MORIN, 2003, p. 65). 
Para Habermas, a noção de emancipação está relacionada a sua teoria do agir comunicativo. Para o filósofo e sociólogo, a racionalidade não é um instrumento de dominação ideológica, mas a capacidade de utilizar a linguagem na orientação das ações e na resolução dos conflitos na sociedade, buscando orientar as ações e resolver os conflitos na relação entre as pessoas. Essa racionalidade daria ensejo a um processo de humanização, fruto do exercício da alteridade e do alargamento do horizonte entre os indivíduos. Essa emancipação se dará quando a ação comunicativa acontecer de forma livre, racional e crítica, ou seja, pelo entendimento. Para o autor, o potencial de emancipação presente na racionalidade seria capaz de constituir uma nova configuração mundial assentada nos direitos humanos. Baert (2009, p. 144) afirma que "a emancipação ocorre em qualquer ocasião em que um indivíduo toma consciência de restrições sociais passadas e as confronta".

Para Warat a educação em seu fim refere-se "ao objetivo de fazer crescer as pessoas em dignidade, autoconhecimento, autonomia e no reconhecimento e afirmação dos direitos da alteridade (principalmente entendidos como o direito à diferença e à inclusão social)" (WARAT, 2003, p. 57), de modo a servir de ferramenta de transformação da consciência social.

A educação é o "mais importante instrumento de "inclusão social" para a "consolidação da cidadania"3 e "concretização dos direitos humanos"; sendo imprescindível para a "tomada de consciência de si mesmo e de sua importância para a comunidade" (GORCZEVSKI, 2010, p. 40).

\begin{abstract}
Entende-se que a tarefa da educação em/para os direitos os direitos humanos deve criar condições de conhecimento e transformação da consciência sobre os direitos como tarefa de produção de novas condições de desenvolvimento e expansão de princípios democráticos do convívio e de formas de cidadania mais exigentes e compatíveis com as conquistas morais dos direitos consagradas em termos normativos nacionais e internacionais (BITTAR; ALMEIDA, 2010, apresentação).
\end{abstract}

Então quando se fala em educação para direitos humanos pretende-se educar para ser mais humano, para ter mais qualidade enquanto gente,

3 Gorczevski refere-se à cidadania como "a qualidade ou o direito do cidadão; e cidadão como o indivíduo no gozo de direitos civis e políticos de um Estado. A ideia de cidadania está sempre ligada a um determinado Estado e em geral expressa um conjunto de direitos que dá ao indivíduo a possibilidade de participar ativamente da vida e do governo de seu Estado". (GORCZEVSKI; TAUCHEN, 2007, p. 13). 
simplesmente ter humanidade para que o sujeito transforme a partir das condições de participação. "Incutir humanidade", para Cantero (2006, p. 263) é a maior das pretensões de todo ideal perquirido pela educação. Afinal, pretende-se preparar a humanidade para a solidariedade e a tolerância de modo a corroborar com a democracia e o compromisso com a paz.

Nas palavras de Rayo:

A educação como vemos se mantém estreitamente unida à forma de organizar e pensar a sociedade. É impensável, portanto, uma educação sem valores, desvinculada de uma dimensão utópica. Educação, ética e política são vértices da construção utópica da paz que necessita de uma cultura de direitos humanos baseada não em qualquer tipo de democracia (representativa, avançada, etc.), mas sim na democracia participativa na perspectiva de um renovado humanismo (Pérez Tapias, 1996). Democracia que tem como principal protagonista a cidadania que participa na elaboração, aplicação e promoção de um conjunto de valores (RAYO, 2004, p. 174-175).

A educação deve reforçar os direitos humanos, as liberdades fundamentais, buscando clarear a compreensão e tolerância entre os povos, para a constante paz social a partir da promoção da dignidade humana de todos. O artigo XXVI da Declaração Universal dos Direitos Humanos no item 2 traz isso bem presente:

\begin{abstract}
Artigo XXVI
1. Toda a pessoa tem direito à educação. A educação deve ser gratuita, pelo menos a correspondente ao ensino elementar fundamental. $O$ ensino elementar é obrigatório. O ensino técnico e profissional dever ser generalizado; o acesso aos estudos superiores deve estar aberto a todos em plena igualdade, em função do seu mérito.

2. A educação deve visar à plena expansão da personalidade humana e ao reforço dos direitos humanos e das liberdades fundamentais e deve favorecer a compreensão, a tolerância e a amizade entre todas as nações e todos os grupos raciais ou religiosos, bem como o desenvolvimento das atividades das Nações Unidas para a manutenção da paz. (grifo nosso)

3. Aos pais pertence a prioridade do direito de escolher o gênero de educação a dar aos filhos (BRASIL, Ministério da Justiça, 2012).
\end{abstract}

"Os fundamentos teórico-metodológicos para a educação em direitos humanos se inserem numa abordagem teórica crítica da educação", objetivando uma "visão crítico-transformadora dos valores, atitudes, relações e práticas sociais e institucionais" (ZENAIDE, 2010, p. 19). Nesse sentido, a educação em direitos humanos proporciona um maior questionamento crítico. 
Ainda, Escobero também chama atenção para a educação em direitos humanos:

\begin{abstract}
Consideramos a educação em direitos humanos como uma importante ferramenta para a prevenção das violações dos direitos humanos, fomentando a conduta e atitudes baseadas na tolerância, na solidariedade e no respeito. Criando sociedades onde a proteção dos direitos humanos seja compreendida por todos - e responsabilidade de todos -, a educação em direitos humanos pode desempenhar um papel importante na proteção destes direitos (ESCOBERO, 1995, Apresentação).
\end{abstract}

Martínez assevera que a incorporação de direitos humanos na educação é um ponto essencial para as sociedades democráticas (MARTíNEZ, 2006, p. 25). Ou seja, não há que se falar em democracia se os direitos humanos não são respeitados. Flávia Piovesan $(2009)^{4}$ vem ao encontro também de tal discurso quando afirma que não existem direitos humanos sem a democracia.

Os direitos humanos são eivados de valores, nascendo com o homem, fazendo parte de sua história. Uma vez que eles não são possibilitados, não há mais que se falar em humanidade, pois o homem deixa de existir. Portanto, eles são anteriores ao Estado e inerentes ao homem, tendo inegável importância, e, embora no Brasil se tenha praticamente todos os direitos humanos positivados na Magna Carta, e por isso facilmente passíveis de exigência, isso não significa que todos se encontram efetivamente concretizados (GORCZEVSKI, 2009, p. 20).

É a partir do conhecimento e da percepção dos direitos humanos que estes poderão ser praticados, e aqui se reafirma mais uma vez o papel de uma educação libertadora nessa construção. É a partir dela que a sociedade pode ser protagonista, desde que aprenda a participar, a se engajar, a ser cidadã, a ser mais humana, de modo a encarar os direitos humanos como orientadores de toda e qualquer conduta.

[...] questão dos direitos humanos é uma questão política e não será resolvida sem a participação consciente, inteligente e objetiva da sociedade. Até porque, por sua imensurável importância, não pode ficar adstrita ao Estado, sequer aos políticos que, em tese, nos representam. A sociedade de forma organizada, e cada cidadão, de forma individual, devem assumir uma postura de compromisso de fazer frente a isso. Afinal toda violação de direitos humanos é um

"Não há direitos humanos sem democracia, tampouco há democracia sem direitos humanos.". (PIOVESAN, 2009) 
crime lesa-humanidade e omitir-se nessa empreitada pode ser um erro perigoso [...]. (GORCZEVSKI, 2009, p. 210)

Sendo assim, cidadania, democracia e direitos humanos estão intrinsecamente vinculados. Ainda, na lição de Gorczevski,

\begin{abstract}
ocorre que a ideia de democracia está indissoluvelmente vinculada às ideias de dignidade, liberdade e igualdade entre os homens, constituindo-se em um corolário de tais princípios; portanto, somente em uma democracia os direitos humanos podem ser efetivamente concretizados. $O$ respeito aos direitos humanos está indissociavelmente unido à democracia porque respeitar os direitos do homem significa respeitar sua liberdade de opinião, de associação, de manifestação e todas as demais liberdades que somente uma democracia permite (GORCZEVSKI, 2011, p. 80).
\end{abstract}

Bem retrata Bobbio (2004) quando menciona que a paz perpétua só pode ser atingida pela democracia e pelos direitos humanos reconhecidos e efetivados internacionalmente. A efetivação dos direitos humanos só tem um terreno fértil em uma real democracia.

Levando-se em conta que a educação não é um instrumento neutro, e que o fato de se optar por uma educação em direitos humanos é uma opção ideológica (GORCZEVSKI, 2009, p. 224), necessário é o cuidado na abordagem deste modelo, onde "o conteúdo ideal é o que encontra o equilíbrio entre um conteúdo puramente de direitos humanos (mais universal) e um de direitos de cidadania (mais local)" (GORCZEVSKI, 2009, p. 227).

\begin{abstract}
Ainda, quanto aos objetivos da educação, convém não esquecer o alerta de Adorno de que a realidade que nos cerca, o mundo contemporâneo [...] impele as pessoas em direção à xenofobia, à intolerância, à barbárie. A sociedade moderna está repleta de fatores que apontam para novos genocídios, que fatalmente ocorrerão se os educadores não tomarem consciência de sua responsabilidade (GORCZEVSKI, 2009, p. 228).
\end{abstract}

A educação em direitos humanos deve estar pautada em preceitos éticos, onde os diferentes instrumentos, que trazem "os direitos contidos na Declaração Universal e nos sistemas normativos, doméstico e internacional, relativos à matéria, são uma conquista da humanidade, que conclama uma luta contínua para estabelecê-los firmemente na consciência dos indivíduos e dos povos" (GORCZEVSKI, 2009, p. 161).

Não deve ser tarefa única do Estado a promoção da educação em direitos humanos, vez que para formar indivíduos éticos solidários, 
comprometidos com a paz social, a justiça e os direitos humanos, necessita-se urgentemente do engajamento de toda a sociedade, de modo que cada cidadão assuma a sua quota de responsabilidade.

A educação é sem dúvida alguma, a responsável pela garantia do
desenvolvimento do homem nos seus mais variados aspectos, não
apenas no cognitivo. Através dela, o ser humano desenvolve,
integralmente, suas aptidões, suas habilidades, apropria-se dos
saberes construídos historicamente, reconstruindo-os e ampliando-os
através de processos críticos e de permanente busca e
aprimoramento (COSTA; RITT, 2008, p. 54)

Educar em direitos humanos é "criar uma cultura preventiva, fundamental para erradicar a violação dos mesmos. Com ela conseguiremos efetivamente dar a conhecer os direitos humanos, distingui-los, atuar a seu favor e, sobretudo, desfrutá-los" (GORCZEVSKI, 2009, p. 221).

Destaca-se 0 art. 205 da Constituição Federal: "A educação, direito de todos e dever do Estado e da família, será promovida e incentivada com a colaboração da sociedade, visando ao pleno desenvolvimento da pessoa, seu preparo para o exercício da cidadania e sua qualificação para o trabalho". Devido à importância assumida pela educação, esta não pode efetivamente ficar à mercê da vontade política dos governos ou do interesse político dos Estados para a sua implementação. Portanto, evidente que a tarefa da educação é de todos - Estado, sociedade e família.

O art. 205 elenca três finalidades da educação: pleno desenvolvimento da pessoa, preparo para o exercício da cidadania e qualificação para o trabalho. Nesse diapasão, pretende um cidadão crítico e atuante, conhecedor e praticante dos seus direitos e deveres, consciente de sua cidadania e protagonista de sua história.

[...] estou absolutamente convicto que sempre que se discute sobre direitos humanos, se está contribuindo para a sua propagação. Eles não possuem outro instrumento de difusão senão as convicções que geram à consciência humana. Equivoca-se quem pensa que os direitos humanos se impõe com as armas, com os decretos arbitrários do poder político ou violando a autonomia das consciências (FERNANDEZ-LARGO, 2006, Presentación).

Também, no âmbito internacional, a educação, enquanto direito fundamental dos indivíduos, aparece em diferentes instrumentos, como na Declaração Universal dos Direitos Humanos, onde seu artigo XXVI traz que 
todo ser humano tem direito à instrução, sendo que esta deve ser "orientada no sentido do pleno desenvolvimento da personalidade humana e do fortalecimento do respeito pelos direitos humanos e pelas liberdades fundamentais" (CEDIN, 2012).

Já no âmbito regional, a Carta da Organização dos Estados Americanos - Carta da OEA - traz como um de seus princípios que "a educação dos povos deve orientar-se para a justiça, a liberdade e a paz" (CEDIN, 2012); a Declaração Americana dos Direitos e Deveres do Homem assevera que

[...] toda pessoa tem direito à educação, que deve inspirar-se nos princípios de liberdade, moralidade e solidariedade humana. Tem, outrossim, direito a que, por meio dessa educação, the seja proporcionado o preparo para subsistir de uma maneira digna, para melhorar o seu nível de vida e para poder ser útil à sociedade. 0 direito à educação compreende o de igualdade de oportunidade em todos os casos, de acordo com os dons naturais, os méritos e o desejo de aproveitar os recursos que possam proporcionar a coletividade e o Estado. Toda pessoa tem o direito de que Ihe seja ministrada gratuitamente, pelo menos, a instrução primária (CEDIN, 2012).

Outra legislação bastante respeitável e de grande importância é o Pacto Internacional sobre Direitos Econômicos, Sociais e Culturais que estabelece

[...] os Estados Partes no presente Pacto reconhecem o direito de toda a pessoa à educação. Concordam que a educação deve visar ao pleno desenvolvimento da personalidade humana e do sentido da sua dignidade e reforçar o respeito pelos direitos do homem e das liberdades fundamentais. Concordam também que a educação deve habilitar toda a pessoa a desempenhar um papel útil numa sociedade livre, promover compreensão, tolerância e amizade entre todas as nações e grupos, raciais, étnicos e religiosos, e favorecer as atividades das Nações Unidas para a conservação da paz. (CEDIN, Art. 13 do Pacto, 2012)

Além destes, existem inúmeros outros documentos internacionais que tratam do tema como: as Convenções de Genebra; a Convenção sobre o Estatuto dos Refugiados; o Pacto dos Direitos Civis e Políticos; o Pacto dos Direitos Econômicos, Sociais e Culturais; a Convenção contra a Tortura e outros Tratamentos ou Penas Cruéis, Desumanas e Degradantes; a Convenção Internacional sobre a Eliminação de Todas as Formas de Discriminação Racial; a Convenção sobre a Eliminação de Todas as Formas de Discriminação contra a Mulher; a Convenção dos Direitos da Criança; a Declaração e Programa de Ação de Viena; a Convenção Interamericana para a Eliminação de Todas as Formas de Discriminação contra as Pessoas 
Portadoras de Deficiência; Conferência das Nações Unidas sobre Meio Ambiente e Desenvolvimento - Eco 92; Conferência Mundial sobre Desenvolvimento Sustentável - Rio+10; e outros (GORCZEVSKI, 2009).

Sendo que o "homem é aquilo que a educação dele faz" (KANT, 1996, p. 15), ela é imprescindível para o desenvolvimento de um Estado, apresentando papel relevante na vida do ser humano. A sua importância é reconhecida desde as "primeiras sociedades politicamente organizadas" (GORCZEVSKI; PIRES, 2006, p. 11). A educação pode ser percebida como uma ferramenta de transformação social, como um processo de constante libertação do ser humano (FREIRE, 2006, p. 75). Tanto é verdade que a partir da Declaração Universal dos Direitos Humanos de 1948, os Estados assumem um compromisso para com a mesma. Nesse contexto, passa-se ao próximo objeto de estudo no presente artigo: o II Plano Nacional de Educação em Direitos Humanos, uma política pública que viabiliza a consolidação de uma cultura de direitos humanos na busca do aperfeiçoamento do Estado Democrático de Direito.

\section{DO II PLANO NACIONAL DE EDUCAÇÃO EM DIREITOS HUMANOS E DA EFETIVAÇÃO DO DIREITOS FUNDAMENTAIS}

No Brasil, no mês de maio de 1996 foi instituído inicialmente o chamado Programa Nacional de Direitos Humanos - PNDH I pelo Ministério da Justiça, com o objetivo de identificar os principais obstáculos à promoção e defesa dos direitos humanos, perquirindo nesse sentido políticas para a implementação dos atos internacionais sobre direitos humanos. Nesse momento também é criada a Secretaria Nacional de Direitos Humanos ${ }^{5}$, marcando a reformulação do Ministério da Justiça, ficando a mesma responsável pela coordenação, gerenciamento e acompanhamento da execução do PNDH I.

Interessante mencionar que o PNDH I fora debatido na $1^{\text {a }}$ Conferência Nacional de Direitos Humanos, após três anos da Conferência de Viena (1993), a qual recomendava em seu plano de ação a elaboração de Programas

5 O Decreto no 2.193, de 07 de abril de 1997, refere-se ao remanejamento dos cargos em comissão que menciona e altera dispositivos do Decreto no 1.796, e 24 de janeiro de 1996, que aprova a Estrutura Regimental do Ministério da Justiça. 
Nacionais de Direitos Humanos. O PNDH I evidenciou e focou-se principalmente nos direitos civis e políticos.

No mês de maio de 2002, ante as 519 propostas de ação sugeridas a partir do PNDH I, promulga-se o Decreto no 4.229, conhecido como Programa Nacional de Direitos Humanos II - PNDH II, ampliando as atribuições e criando propostas de ações governamentais. No programa reformulado há a inclusão dos direitos sociais, econômicos e culturais, preocupando-se com as propostas capazes de ter uma concretude com as políticas públicas e a destinação de recursos para sua execução. O PNDH II foi refletido como uma política de Estado e não de um governo, sendo publicado no último ano do governo Fernando Henrique Cardoso. Entretanto, há de se destacar que não teve grande influência na formulação de políticas públicas daquela época, tendo em vista que logo assume o governo Lula. (CICONELLO; PIVATO; FRIGO, 2009, p. 7)

Em 2008, a Secretaria Especial dos Direitos Humanos elaborou uma atualização para o PNDH II, trazendo-o para discussão na $11^{\text {a }}$ Conferência Nacional de Direitos Humanos e procurando sistematizar o que fora realizado desde o ano de 2002. Entretanto para surpresa, soube-se que muitos gestores de diversos ministérios sequer conheciam o PNDH até então (CICONELLO; PIVATO; FRIGO, 2009, p. 8). Assim, na 11a Conferência Nacional de Direitos Humanos abriu-se um espaço mais abrangente para discussão do Programa, sendo viabilizada a articulação da sociedade civil e dos movimentos sociais para a construção de um acordo político. A retomada do Programa necessitava de um debate maior com o governo sobre "quais seriam suas bases, como seria conduzido o processo de mobilização e que garantias seriam apresentadas sobre seu processo de implementação" (CICONELLO; PIVATO; FRIGO, 2009, p. 8). A partir da Conferência, a participação de diversos sujeitos foi possibilitada, tendo sido realizado debates em 27 estados, contando com de mais de quatorze mil participantes, proporcionando dessa maneira a incorporação de várias necessidades iminentes para a construção de um país preocupado com o respeito aos direitos humanos.

O Programa Nacional de Direitos Humanos III - PNDH III (Decreto no 7.037/2009) teve como principal desafio apresentar-se como um programa que "considerasse a indivisibilidade e a interdependência dos Direitos Humanos em 
todas as suas dimensões: civis, políticas, econômicas, sociais, culturais, sexuais, reprodutivas e ambientais" (CICONELLO; PIVATO; FRIGO, 2009, p. 8). O seu debate destacou as "dimensões de desigualdade, violência, modelo de desenvolvimento, cultura e educação em Direitos Humanos, democracia, monitoramento e direito à memória e Justiça" (CICONELLO; PIVATO; FRIGO, 2009, p. 8).

Portanto, o principal desafio do PNDH III foi "transformá-lo em uma política de Estado e não de um governo ou até mesmo de uma Secretaria Especial de Direitos Humanos" (CICONELLO; PIVATO; FRIGO, 2009, p. 11), devendo servir de "instrumento de referência para a formulação de programas e ações tanto para o Poder Executivo, como para os Poderes Legislativo e Judiciário" (CICONELLO; PIVATO; FRIGO, 2009, p. 11).

Entretanto, ainda em paralelo à construção do vários PNDHs, no ano de 2003 um comitê formado por especialistas, representantes da sociedade civil, de instituições públicas e privadas inicia a elaboração do I Plano Nacional de Educação em Direitos Humanos (PNEDH). Em 2005 foram realizados encontros estaduais para difundi-lo, que resultaram em contribuições da sociedade para aperfeiçoar também o documento.

Já no ano de 2006, por iniciativa da Secretaria Especial dos Direitos Humanos é aprovado o II Plano Nacional de Educação em Direitos Humanos, de forma conjunta entre o Ministério da Justiça, o Ministérios da Educação, a Secretaria Especial de Direitos Humanos, o Comitê Nacional de Educação em Direitos Humanos e a Organização das Nações Unidas para a Educação, a Ciência e a Cultura (UNESCO). Logo, cumprindo as diretrizes internacionais da UNESCO, o Brasil elabora então a última versão do Plano Nacional de Educação em Direitos Humanos (PNEDH), o qual tende a representar o compromisso atual do Estado com a concretização dos direitos humanos. Tal Plano trata-se de uma política pública que tem dois sentidos principais: primeiro, consolidando uma proposta de um projeto de sociedade baseada nos princípios da democracia, cidadania e justiça social; segundo, reforçando um instrumento de construção de uma cultura de direitos humanos, entendida como um processo a ser apreendido e vivenciado na perspectiva da cidadania ativa (BRASIL, 2007). 
O II PNEDH representa um compromisso contínuo de implementação de política pública viabilizadora da consolidação de uma cultura de direitos humanos na busca do aperfeiçoamento do Estado Democrático de Direito. Afinal, é somente em uma real democracia ${ }^{6}$ que os direitos humanos podem ser efetivados.

Destaca-se que no II PNEDH é contemplado 5 eixos de atuação: Educação Básica; Educação Superior; Educação Não-Formal; Educação dos Profissionais dos Sistemas de Justiça e Segurança Pública e Educação e Mídia. Ademais, a sua estrutura apresenta diretrizes próprias, objetivos, linhas de ação e concepções. Reclama a importância da valorização de uma educação para direitos humanos, representando uma "conquista histórica da maior relevância no âmbito do Art. 26, item 2, da DUDH, sendo um marco." (FISCHMANN, 2009, p. 217).

O II PNEDH tem por objetivos gerais: a) destacar o papel estratégico da educação em direitos humanos para o fortalecimento do Estado Democrático do Direito; b) enfatizar o papel dos Direitos Humanos na construção de uma sociedade justa, equitativa e democrática; c) encorajar o desenvolvimento de ações de educação em direitos humanos pelo poder público e a sociedade civil por meio de ações conjuntas; d) contribuir para a efetivação dos compromissos nacionais e internacionais com a educação em direitos humanos; e) estimular a cooperação nacional e internacional na implementação de ações de educação em direitos humanos; f) propor a transversalidade da educação em direitos humanos nas políticas públicas, estimulando o desenvolvimento institucional e interinstitucional das ações previstas no PNEDH nos mais diversos setores; g) avançar nas ações e propostas do Programa Nacional de Direitos Humanos que se referem às questões da educação em direitos humanos; h) orientar políticas educacionais direcionadas para a constituição de uma cultura de direitos humanos; i) estabelecer objetivos, diretrizes e linhas de ações para a elaboração de programas e projetos na área da educação em direitos humanos; j) estimular a reflexão, o estudo e a pesquisa voltados para a

6 Destaca-se que Habermas veicula a proteção dos direitos e a participação política à sobrevivência da democracia, vez que esta é percebida como um "grande ideal de vida ética" (AUDARD, 2005, p. 111). Portanto, falar em democracia é invocar também os direitos humanos. 
educação em direitos humanos; $k$ ) incentivar a criação e o fortalecimento de instituições e organizações nacionais, estaduais e municipais voltadas a educação em direitos humanos; I) balizar a elaboração, implementação, monitoramento, avaliação e atualização dos Planos de Educação em Direitos Humanos dos Estados e Municípios; m) incentivar o acesso às ações de educação em direitos humanos a pessoas com deficiência. (BRASIL, 2007).

O II PNEDH busca, portanto comprometer uma cultura de respeito e promoção dos direitos humanos voltando-se ao desenvolvimento social e emocional, ao entendimento e respeito mútuo, à responsabilidade, dignidade e autoestima, sendo necessário que isso ocorra tanto pela socialização de conteúdos como por meio de experiências, utilização de materiais, métodos pedagógicos e processos participativos e democráticos de gestão. (MONTEIRO, 2008, p. 30). Definitivamente, o II PNEDH vem para propor a difusão da cultura dos direitos humanos no Brasil, tornando mais conhecido valores solidários, cooperativos e de justiça social, uma vez que a funcionalidade do Estado Democrático de Direito necessita impreterivelmente do fortalecimento da sociedade civil, para que esta consiga melhor identificar seus anseios e demandas, perquirindo por suas conquistas, políticas públicas eficientes para todos. Nesse contexto entra o papel primordial da educação para os direitos humanos.

\section{CONSIDERAÇÕES FINAIS}

Os direitos humanos são valores e nascem com o homem, fazendo parte de cada momento da sua história. Uma vez que eles não são possibilitados, não há mais que se falar em "humanidade", pois o homem perde o seu real sentido de existência. Portanto, destacou-se no presente artigo que os direitos humanos são anteriores ao Estado e, portanto, inerentes ao ser humano. Eles têm inegável importância, e, no Brasil, embora se tenha praticamente todos aqueles positivados na Magna Carta, e por isso facilmente passíveis de exigência, isso não significa que se encontrem necessariamente concretizados. Ainda muitos são os obstáculos existentes para a concretização dos direitos humanos e fundamentais. Se assim não o fosse, não haveria inúmeras 
organizações trabalhando em sua defesa na atualidade, nem mesmo políticas públicas preocupadas com a sua difusão.

Enquanto processo também de sociabilização, a educação pode auxiliar na concretização dos direitos humanos uma vez que se propõe à formação de cidadãos éticos, solidários, dotados de alteridade, preocupados com a paz e a justiça.

A educação em direitos humanos abordada no presente artigo é frisada como uma ferramenta de libertação/emancipação dos indivíduos, na medida em que proporciona a retomada de valores como a ética e a justiça, aparentemente tão esquecidos. Ademais, a educação deve reforçar os direitos humanos, as liberdades fundamentais, buscando desse modo, auxiliar na compreensão e na tolerância entre os povos, para a constante paz social e dignidade humana no Estado Democrático. Ela tem um papel primordial nesse sentido quando viabiliza um educar para ser mais humano, para ter mais qualidade enquanto gente. A educação é tarefa de todos: escola, sociedade e família, não podendo ficar à mercê da vontade política dos governos e dos Estados.

Nesse sentido, o II Plano Nacional de Educação em Direitos Humanos frisa muito ser uma política de Estado, e não de governo, sendo os seus objetivos, um compromisso assumido perante a comunidade internacional. Apresenta-se como um instrumento para a efetiva concretização dos direitos humanos e fundamentais, merecendo, portanto, tal política pública, um olhar especial por parte da sociedade, assumindo o seu protagonismo social também na história.

\section{REFERÊNCIAS}

ALEXY, Robert. Constitucionalismo discursivo. Tradução de Luís Afonso Heck. 2 ed. rev. Porto Alegre: Livraria do Advogado, 2008.

ARENDT, Hannah. A Crise na Educação. In: Entre o Passado e o Futuro. Trad. Mauro W. Barbosa. 6 ed. São Paulo: Perspectiva, 2007.

AUDARD, Catherine. O princípio de legitimidade democrática e o debate Rawls-Habermas. In: ROCHLITZ, Rainer (Coord.). Habermas: o uso público da razão. Tradução Léa Novaes. Rio de Janeiro: Tempo Brasileiro, 2005. 
BAERT, Patrick. "Jürgen Habermas" in SCOTT, John (organizador). 50 Grandes Sociólogos Contemporâneos. São Paulo: Contexto, 2009.

BITTAR, Eduardo Carlos Bianca; ALMEIDA, Guilherme Assis de. Minicódigo de direitos humanos. (orgs.). Associação Nacional de Direitos Humanos (ANDHEP). Secretaria Especial de Direitos Humanos da Presidência da República (SEDH). Brasília: Teixeira Gráfica e Editora, 2010.

BOBBIO, Norberto. A era dos direitos. Tradução de Carlos Nelson Coutinho. Apresentação de Celso Lafer. Nova Edição. 10 impressão. Rio de Janeiro: Elsevier, 2004.

BRASIL. Secretaria Especial de Direitos Humanos. Plano Nacional de Educação em Direitos Humanos-PNEDH. Brasília: Secretaria Especial dos Direitos Humanos, Ministério da Educação, Ministério da Justiça, Unesco, 2007.

BRASIL. Ministério da Justiça. Declaração Universal dos Direitos Humanos. Disponível em: http://portal.mj.gov.br/sedh/ct/legis_intern/ddh_bib_inter_universal.htm. Acesso em: 30 outubro 2012.

CANOTILHO, José Joaquim Gomes. Direito Constitucional e a teoria da constituição. 2 ed. Coimbra: Almedina, 1998.

CANTERO, Fernando Gil. Didáctica de la educación em derechos humanos. Sistema educativo español. In: RIBOTTA. Silvina (ed.) Educación em Derechos Humanos. La asignatura pendiente. Madrid: Dykinson, 2006.

CENTRO de Direito Internacional (Cedin). Art. XXVI da Declaração Universal dos Direitos Humanos da ONU de 10 de dezembro de 1948. Disponível em: http://www.ce din.com.br/website/internas/legislação. Acesso em: 08 maio 2012.

Art. 13 do Pacto Internacional sobre Direitos Econômicos, Sociais e Culturais. Disponível em: http://www.cedin.com.br/website/in ternas/legislação. Acesso em: 08 maio 2012.

CICONELO, Alexandre; PIVATO, Luciana; FRIGO, Darci. Programa Nacional de Direitos Humanos: efetivar direitos e combater desigualdades. In: Revista Direitos Humanos. Vol.4, Dez/2009. Brasília: Secretaria Especial dos Direitos Humanos, 2009.

COSTA, Marli Marlene Moraes da; RITT, Caroline Fockinki. Educação como um direito fundamental e social. In: GORCZEVSKI, Clovis; REIS, Jorge Renato dos (Orgs.). Direitos fundamentais sociais como paradigmas de uma sociedade fraterna: constitucionalismo contemporâneo. Santa Cruz do Sul: Editora IPR, 2008. 
DIMOULIS, Dimitri; MARTINS, Leonardo. Teoria geral dos direitos fundamentais. 3 ed. rev.atual. e ampl. São Paulo: Editora Revista dos Tribunais, 2011.

ESCOBERO, Santos Jorna. Presidente da Seç̧ão Espanhola da Anistia Internacional. In Presentación. Educación en Derechos Humanos. Propuestas Didácticas. Madrid: Sección Española de Amnistia Internacional. 1995.

FERNANDEZ-LARGO, Antonio Osuna. Presentación de GORCZEVSKI, Clovis. Direitos humanos. Dos primórdios da humanidade ao Brasil de hoje. Porto Alegre: Imprensa Livre, 2006.

FISCHMANN, Roseli. Direitos Humanos e Educação. In: 60 anos da Declaração Universal dos Direitos Humanos: Conquistas do Brasil. Org. GIOVANNETTI, Andrea. Brasília: Fundação Alexandre de Gusmão, 2009.

FRANCISCO, Maria de Fátima Simões. Preservar e renovar o mundo. In: Revista Educação. Hannah Arendt pensa a educação. Especial Biblioteca do professor no 4. 2 ed. São Paulo: Segmento, 2008.

FREIRE, Paulo. Ação cultural para a liberdade e outros escritos. São Paulo: Paz e Terra, 2006.

Política e educação: ensaios. Coleção Questões de nossa época. V. 23. 5 ed. São Paulo: Cortez, 2001a. Disponível em: http://www.paulofreire.ce.ufpb.br/paulofreire/Controle?op=detalhe\&tipo=Livro\&i $\mathrm{d}=1238$. Acesso em 02 setembro 2012.

Direitos Humanos e Educação Libertadora. In: FREIRE, Ana Maria Araújo (Org.). Pedagogia dos sonhos possíveis. São Paulo: UNESP, $2001 b$.

Pedagogia da Autonomia: saberes necessários à prática educativa. 25 ed. São Paulo: Paz e Terra, 1996. Disponível em: http://portal.mda.gov.br/portal/saf/arquivos/view/ater/livros/Pedagogia_da_Auto nomia.pdf. Acesso em 1ํ setembro 2012.

FISCHMANN, Roseli. Direitos Humanos e Educação. In: 60 anos da Declaração Universal dos Direitos Humanos: Conquistas do Brasil. Org. GIOVANNETTI, Andrea. Brasília: Fundação Alexandre de Gusmão, 2009.

GORCZEVSKI, Clovis. A necessária revisão do conceito de cidadania [recursoeletrônico]: movimentos sociais e novos protagonistas na esfera pública democrática / Clovis Gorczevski e Nuria Belloso Martin. - Santa Cruz do Sul: Edunisc, 2011.

A educação para os direitos humanos como política pública de combate a violência na sociedade pós-moderna. In: GORCZEVSKI, Clovis. (org.) Direitos humanos e participação política. Porto Alegre: Imprensa Livre, 2010. 
Direitos humanos, educação e cidadania: conhecer, educar, praticar. Santa Cruz do Sul: Edunisc, 2009.

PIRES, Francisco Luiz da Rocha Simões Pires. In: GORCZEVSKI, Clovis. (org.) Direito \& Educação. Porto Alegre: UFRGS, 2006.

TAUCHEN, Gionara. Educar para os direitos humanos, ou para a cidadania? In: GORCZEVSKI, Clovis. (org.). Direitos Humanos, Educação e Cidadania. Porto Alegre: UFRGS, 2007.

KANT, Emmanuel. Sobre a Pedagogia. Piracicaba: Inimep, 1996.

LEAL, Rogério Gesta. Direitos Humanos no Brasil: desafios à democracia. Porto Alegre: Livraria do Advogado; Santa Cruz do Sul: Edunisc, 1997.

MARTÍNEZ, Gregório Peces-Barba. "La incorporación del derecho y de los derechos humanos en la educación". In: RIBOTTA. Silvina (ed.) Educación en Derechos Humanos. La asignatura pendiente. Madrid: Dykinson, 2006.

MONTEIRO, Aída. O Plano nacional de educação em direitos humanos. In: BRASIL. Presidência da República. Secretaria Especial de Direitos Humanos. Brasil Direitos Humanos 2008: a realidade do país aos 60 anos da Declaração Universal. Brasília: SEDH, 2008.

MORIN, Edgar. A cabeça bem feita: repensar a reforma, reformar o pensamento. Trad. Eloá Jacobina. Rio de Janeiro: Bertrand Brasil, 2003.

PÉREZ-LUÑO, Antonio Enrique. Derechos humanos, Estado de Derecho y Constitución. 6 ed. Madrid: Tecnos, 1999.

. Los derechos fundamentales. 8 ed. Madrid: Tecnos, 2005.

PIOVESAN, Flávia. Direitos Humanos: desafios e perspectivas contemporâneas. Rev. TST, Brasília, vol. 75, no 1, jan/mar 2009. Disponível em:

http://www3.tst.jus.br/Ssedoc/PaginadaBiblioteca/revistadotst/Rev_75/Rev_75_ 1/piovesanflavia.pdf. Acesso em 24 julho 2012.

RAYO, José Tuvilla. Educação em direitos humanos: rumo a uma perspectiva global. Trad. Jussara Haubert Rodrigues. Porto Alegre: Artmed, 2004.

SADER, Emir. Contexto histórico e educação em direitos humanos no Brasil: da ditadura à atualidade. In: SILVEIRA, Rosa Maria Godoy; DIAS, Adelaide Alves; FERREIRA, Lúcia de Fátima Guerra; FEITOSA, Maria Lúcia Pereira de Alencar Mayer; ZENAIDE, Maria de Nazaré Tavares. (Orgs.). Educação em Direitos Humanos: fundamentos teórico-metodológicos. Brasília: Secretaria Especial dos Direitos Humanos, 2010. 
SÁNCHEZ RUBIO, David. Fazendo e desfazendo direitos humanos. Tradução Clovis Gorczevski. Direito \& Sociedade Contemporânea. Vol. 9. 1 ed. Santa Cruz do Sul: Edunisc, 2010.

SARLET, Ingo Wolfgang. A eficácia dos direitos fundamentais: uma teoria geral dos direitos fundamentais na perspectiva constitucional. 10 ed. ver. atual. e ampl. Porto Alegre: Livraria do Advogado, 2009.

SARMENTO, Daniel. Direitos fundamentais e relações privadas. Rio de Janeiro: Lumen Juris, 2004.

WARAT, Luis Alberto. Direitos Humanos: Subjetividade e Práticas Pedagógicas. In: Educando para os Direitos Humanos: Pautas pedagógicas para a Cidadania na Universidade. Org. SOUSA Jr., José Geraldo de. São Paulo: Síntese, 2003.

ZENAIDE, Maria de Nazaré Tavares. Introdução. In: SILVEIRA, Rosa Maria Godoy; DIAS, Adelaide Alves; FERREIRA, Lúcia de Fátima Guerra; FEITOSA, Maria Lúcia Pereira de Alencar Mayer; ZENAIDE, Maria de Nazaré Tavares. (Orgs.). Educação em Direitos Humanos: fundamentos teórico-metodológicos. Brasília: Secretaria Especial dos Direitos Humanos, 2010.

Recebido para publicação: 02/05/2013

Aceito para publicação: 17/06/2013 